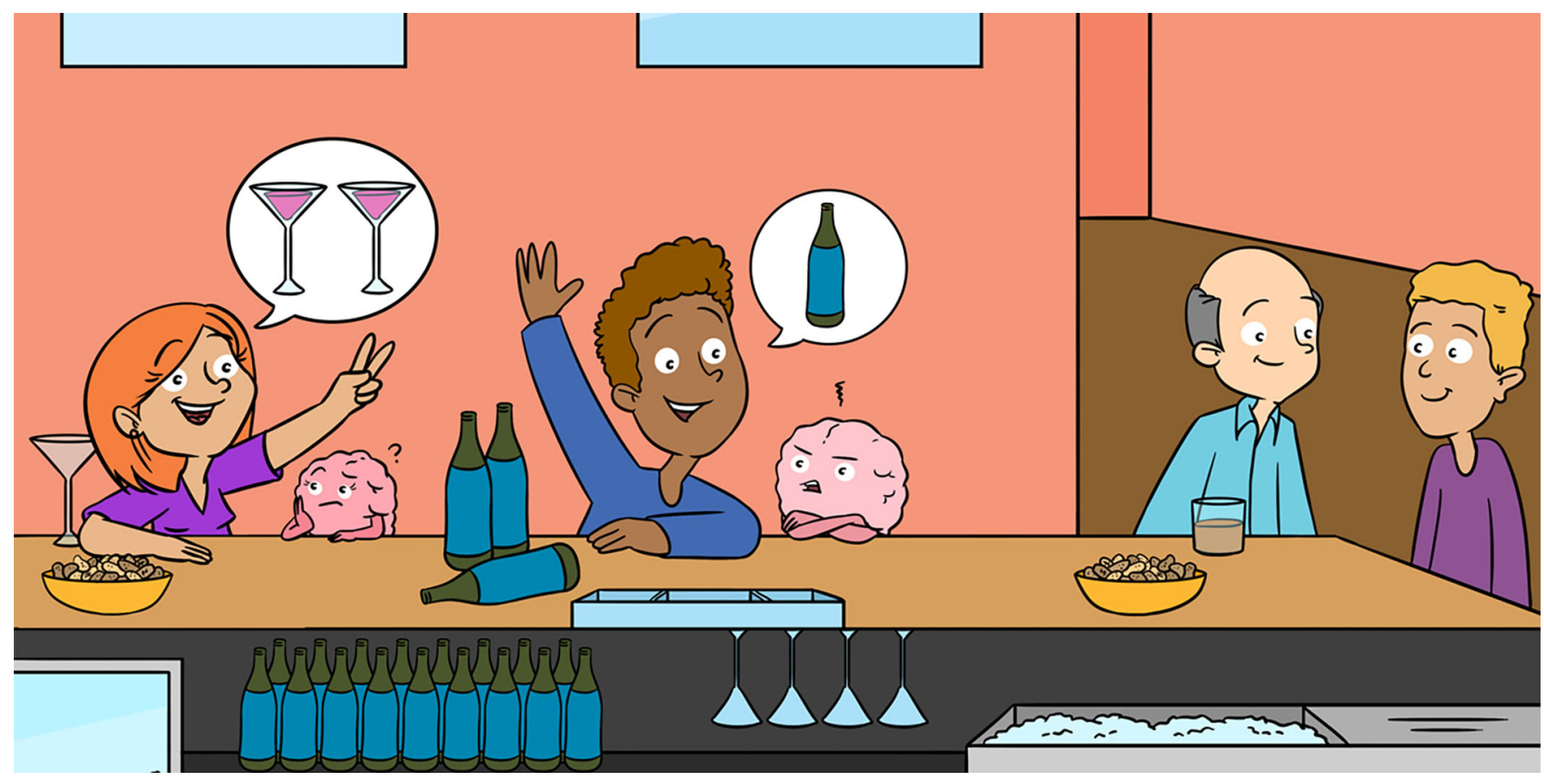

\title{
HOW DOES ADOLESCENT ALCOHOL USE AFFECT THE DEVELOPING BRAIN?
}

Jennifer Debenham ${ }^{1 *}$, Cath Chapman ${ }^{1}$, Ruby McIntyre ${ }^{1,2}$, Louise Birrell ${ }^{1}$, Katrina Champion ${ }^{1}$ and Nicola Newton ${ }^{1}$

${ }^{1}$ The Matilda Centre for Research in Mental Health and Substance Use, University of Sydney, Sydney, NSW, Australia

${ }^{2}$ Rosebank College, Sydney, NSW, Australia

YOUNG REVIEWERS:

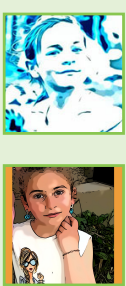

ALLIE

AGE: 12

BASMA

AGE: 7
What does it mean to have a developing brain and why do drugs, including alcohol, impact adolescents differently than adults? It is a common misconception that drugs have the same effects on everyone, however the truth is, the biological playing field is not level-we all have a different susceptibility to drug-related harm. This is particularly true for young people who are under 25 , because their brains are still under construction. In this article, we investigate the characteristics of the developing brain and assess the impact alcohol on the brain. We also summarize some ways that alcohol-related harm to the brain can be minimized.

\section{THE ARCHITECTURE OF THE ADOLESCENT BRAIN}

There is a growing body of research indicating that the experiences we engage in during the period called adolescence, when we are 10-19 years old, pave the way for brain health into adulthood. Over 


\section{ADOLESCENT}

Any person aged between 10 and 19 years.

\section{NEUROPLASTICITY}

The ability of the brain to change continuously based on experiences.

\section{NEURON}

A brain cell.

\section{PRUNING}

The removal of unneeded neural connections that occurs with age.

\section{MYELINATION}

A process of brain development that helps to insulate brain cells to improve

their communication

\section{SYNAPTOGENESIS}

The birth of new connections (synapses) between neurons.

\section{PREFRONTAL}

\section{CORTEX}

The part of the brain responsible for sophisticated, complex thinking. the adolescent years, the brain is constantly responding and adapting to the world around us, so that it can lose what it does not need and strengthen what it does need. We strive towards leaner, meaner, and more efficient brain activity so that our brains can conserve energy while functioning to the best of their ability. This has been called the "use it or lose it" principle and it is responsible for a phenomenon called neuroplasticity, which is the brain's plastic, pliable property that allows it to change over time.

There are three processes that contribute to high neuroplasticity during youth. First, we are born with a massive number of jumbled brain cells called neurons that are not necessarily working together. This consumes a lot of energy and is not very efficient. Through a process called pruning, the neurons that we no longer use are tossed out, similar to a landscaper trimming a wild hedge. Second, to increase the speed of neuron communication, a process called myelination occurs, which coats neurons in a fatty outer layer, similar to insulating a copper wire for more rapid electrical conductance. Third, another process called synaptogenesis occurs, in which new connections between neurons, called synapses, are formed. These three processes-pruning, myelination, and synaptogenesis-help to connect the different regions of the brain, similar to the way we pave new roads to connect different suburbs. Did you know that this process of brain development occurs throughout childhood and adolescence, and does not wind up until around 25 years of age $[1,2]$ ?

Interestingly, the brain generally develops from the back to the front. The back of the brain, called the hind brain, is responsible for the basic functions we need to survive, like breathing, heart rate, and coordination. The middle part of the brain, called the subcortical mid brain, is responsible for primitive instincts like activating emotions, storing memories, feeling pleasure, and maintaining a constant internal environment. The front of the brain, called the fore brain, is responsible for sophisticated, high-level thinking, reasoning, impulse control, managing emotions, and decision-making. The fore brain is the last part of the brain to fully develop. This is easy to remember because development goes from the most basic to the most complex, moving from back to front (Figure 1)!

Sitting at the very front of the fore brain is the prefrontal cortex. During adolescence, the prefrontal cortex is still developing, which makes it more vulnerable to the negative impacts of things like drugs and alcohol. Even though adults have less neuroplasticity and do not learn as quickly as young people do, their brains are far more protected against the damaging neurological effects of substances. 


\section{Figure 1}

The developing brain Three regions of the brain develop in succession, from most basic to most complex during adolescence. First, the hind brain develops, then the mid brain, and last, the fore brain.

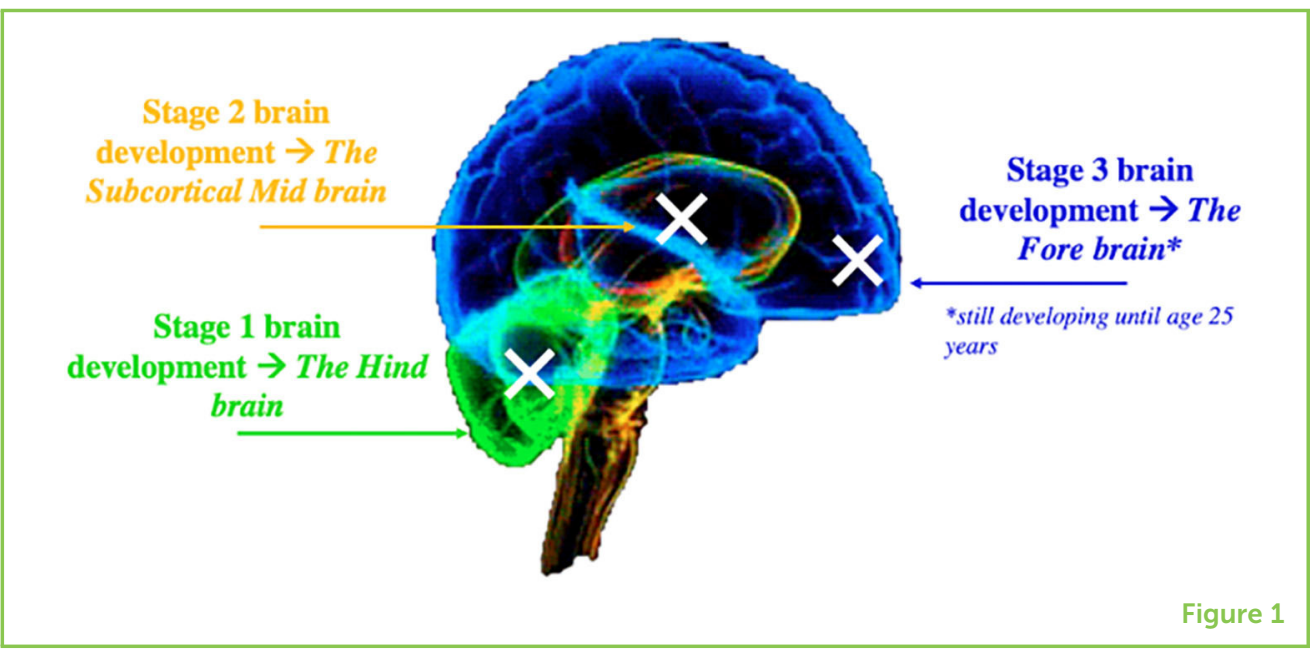

\section{ALCOHOL INTOXICATION: WHAT HAPPENS DURING A NIGHT OUT DRINKING?}

Alcohol is a neural depressant, meaning it reduces brain activity. The more a person drinks, the less active his or her brain becomes, and this tends to happen from the front of the brain to the back, meaning the most recently developed, or still developing, part of the brain is affected first. Symptoms of intoxication result from alcohol inhibiting different regions of the brain (see Figure 2).

- At first, alcohol reduces activity in the fore brain; the ability to plan, problem solve, and navigate conflicting emotions is greatly reduced. People tend to feel less inhibited and might say things they normally would not.

- Next, alcohol reaches the subcortical mid brain; speech becomes slurred, emotions can go unchecked, and memories are not formed well.

- Finally, after excessive drinking, alcohol can reach the hind brain; coordination plummets, heart rate slows down, and in extreme cases, alcohol can depress activity in the breathing center of the brain to dangerously low levels - this can bring on an alcohol-induced coma and overdose.

Although the precise blood alcohol concentrations that cause these changes vary between individuals (with food consumption, body weight, and gender being some of the factors influencing the breakdown and concentration of alcohol in the body), the higher the volume of alcohol and higher the rate of consumption, the more likely it is that alcohol will reach all three brain regions. 
Figure 2

Alcohol intoxication affects brain activity

The fore brain is affected first, followed by the mid brain and the hind brain.

\section{BINGE DRINKING}

Consuming a large amount of alcohol in a short period, causing a blood alcohol concentration level of at least 0.08 per $100 \mathrm{~g}$ of blood.

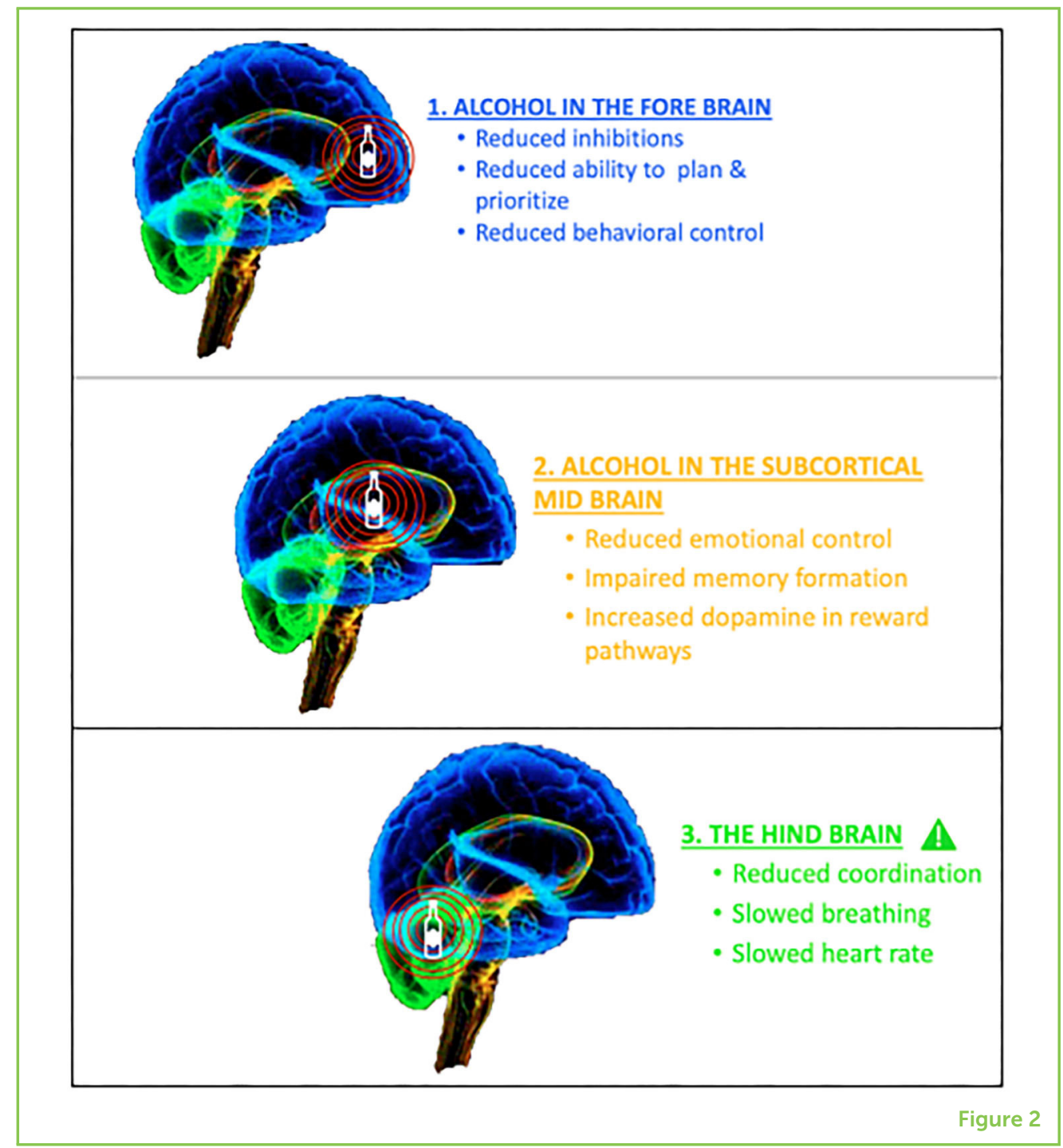

\section{CAN WE REDUCE THE HARM OF DRINKING ALCOHOL?}

First and foremost, people who drink should shift gears away from drinking to excess (called binge drinking), especially if their brains are still developing! Regardless of your decision to drink or not, it is always a good idea to devise a plan before entering a social environment. This is because we tend to make riskier decisions when we are in the company of friends compared to when we are alone [2]. Because the same amount of alcohol affects people differently, and even the same person differently on separate occasions, it is important to be aware of the signs of intoxication. This way, regardless of the dose of alcohol, you can identify levels of drunkenness and respond accordingly. Many people make creative attempts to sober up, such as eating bread and coffee beans or taking a cold shower, however nothing but time can bring down blood alcohol concentration and these supposed cures can do more harm than good [2]. Finally, mixing alcohol with other drugs can be very dangerous, and this is particularly true for other depressants, such as prescription pain medication. Mixing other 
depressants with alcohol can lead to increased neural depression in the hind brain and potentially an overdose. Remember, even if drinking alcohol is legal, that does not mean it is not harmful! If you are concerned for someone's well-being, you can always take that person to the emergency room, and in a crisis situation, do not hesitate to call an ambulance.

\section{WHAT HAPPENS WHEN ALCOHOL IS USED LONG-TERM?}

Heavy, long-term alcohol use can have very serious effects on the brain. Research suggests that binge drinking can cause the brains of young people to develop more slowly [3]. This is partly because alcohol may disrupt synaptogenesis, pruning, and myelination, which may change the structures of certain brain regions. Structural and functional changes in the fore brain and the subcortical mid brain are closely linked to heavy alcohol use during adolescence [3]. These physical changes are often accompanied by changes in the way people think. Did you know that the earlier a person first uses alcohol, the higher his or her chances are of developing problems with alcohol or drugs later in life? It seems that alcohol's impact on the brain is proportionate to the age of first use, as well as the frequency and amount consumed.

Over time, the brain learns to cope with excessive long-term alcohol use through a series of changes, in which it tries to counteract the constant neural depression by producing increased amounts of stimulating brain chemicals. Unfortunately, when alcohol is no longer consumed, the brain still produces the stimulating chemicals and there can be excessive neural excitation, resulting in a seizure-this can be fatal [4]. This is the reason why, in many cases, people who have an alcohol use disorder are carefully medicated off alcohol, so that they do not experience excessive neural excitation. Luckily, the brain's neuroplasticity helps with recovery from excessive alcohol use. There is evidence that, with abstinence, some of the structural changes in the brain caused by alcohol might be reversible [4].

\section{CONCLUSION}

Research has made it clear that frequent alcohol use during adolescence is linked to changes in the way the brain looks and functions. However, we have only just scraped the surface in our understanding of the brain and the more we learn, the more questions we have to what extent is it possible for the brain to recover after heavy alcohol use? What makes some people more vulnerable to alcohol-related harm than others? These are just some of the many questions that scientists hope to answer in the coming years. Until then, it is up to young people to educate themselves and minimize 
the harms of alcohol and drugs in their own lives and the lives of their peers.

\section{AUTHOR CONTRIBUTIONS}

JD and CC developed the concept. JD and RM conducted the preliminary research for the article and all researchers (JD, RM, CC, LB, $\mathrm{KC}$, and NN) supported the article write-up and editing process.

\section{REFERENCES}

1. Casey, B., Tottenham, N., Liston, C., and Durston, S. 2005. Imaging the developing brain: what have we learned about cognitive development? Trends Cogn. Sci. 9:104-10. doi: 10.1016/j.tics.2005.01.011

2. Marlatt, G. A., and Witkiewitz, K. 2002. Harm reduction approaches to alcohol use: health promotion, prevention, and treatment. Addict. Behav. 27:867-86. doi: 10.1016/s0306-4603(02)00294-0

3. Lees, B., Mewton, L., Stapinski, L. A., Squeglia, L. M., Rae, C. D., and Teesson, M. 2019. Neurobiological and cognitive profile of young binge drinkers: a systematic review and meta-analysis. Neuropsychol. Rev. 29:357-85. doi: 10.1007/s11065-019-09411-w

4. Seo, D., and Sinha, R. 2015. Neuroplasticity and predictors of alcohol recovery. Alcohol Res. 37:143-52.

SUBMITTED: 30 January 2020; ACCEPTED: 01 September 2020; PUBLISHED ONLINE: 23 October 2020.

EDITED BY: Alessandro Antonietti, Catholic University of the Sacred Heart, Italy

CITATION: Debenham J, Chapman C, Mclntyre R, Birrell L, Champion K and Newton N (2020) How Does Adolescent Alcohol Use Affect the Developing Brain? Front. Young Minds 8:525155. doi: 10.3389/frym.2020.525155

CONFLICT OF INTEREST: The authors declare that the research was conducted in the absence of any commercial or financial relationships that could be construed as a potential conflict of interest.

COPYRIGHT @ 2020 Debenham, Chapman, Mclntyre, Birrell, Champion and Newton. This is an open-access article distributed under the terms of the Creative Commons Attribution License (CC BY). The use, distribution or reproduction in other forums is permitted, provided the original author(s) and the copyright owner(s) are credited and that the original publication in this journal is cited, in accordance with accepted academic practice. No use, distribution or reproduction is permitted which does not comply with these terms. 

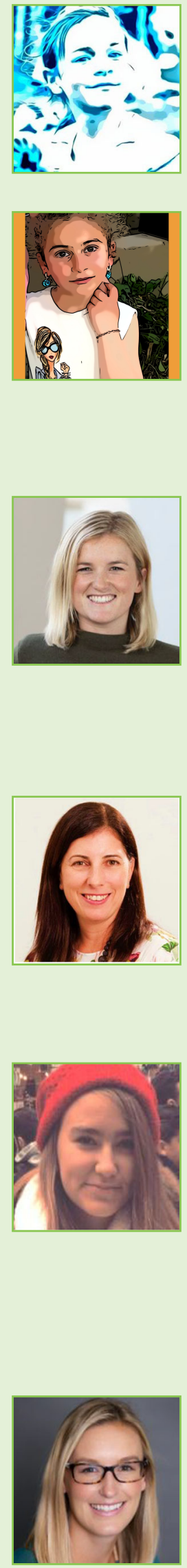

\section{YOUNG REVIEWERS}

\section{ALLIE, AGE: 12}

My name is Allie and I am 12 years old. Both of my parents are animal scientists and my favorite subjects in school are math and science. Outside of school, I love to read and enjoy running cross country.

\section{BASMA, AGE: 7}

I am a 7-years-old girl. I grew up in Lebanon. I love Science and dancing. I know a lot about agriculture. My favorite sport is karate. My sister reads scientific articles, I think I understand $50 \%$ of the conclusion but sometimes less. My name means "smile," and I love it so much.

\section{AUTHORS}

\section{JENNIFER DEBENHAM}

Ms. Jennifer Debenham is a Ph.D. student at the Matilda Centre for Research in Mental Health and Substance Use at the University of Sydney in Australia. Jennifer is reviewing the neurodevelopmental impact of drug use on the adolescent brain and is trying to better understand the nature of the relationship between drug use and related social harms. Jennifer is interested in translating neuroscience research into non-judgmental, useful resources for young people. *jennifer.debenham@ sydney.edu.au

\section{CATH CHAPMAN}

A/Prof. Cath Chapman is Director of Research Development and Strategy at the Matilda Centre for Research in Mental Health and Substance Use at the University of Sydney in Australia. She is also Program Director of an NHMRC Centre of Research Excellence in the Prevention and Early Intervention of Mental Illness and Substance Use (PREMISE). Her research focuses on the way we can use data to improve mental health and prevent substance use problems among young people.

\section{RUBY MCINTYRE}

Ms. Ruby Mclntyre is a driven student in grade 10, studying at RoseBank College Sydney, Australia. Whilst completing her high school education, Ruby has pursued her interest in public health and psychology through work experience internship at the Matilda Centre for Research into Mental Health and Substance Use at the University of Sydney, Australia. Here, Ruby helped write the current article and gained experience in projects spanning across prevention and early intervention, and she looks forward to developing her interest and skills to address youth-related issues in the future.

\section{LOUISE BIRRELL}

Dr. Louise Birrell is a Post-doctoral Research Fellow within the Matilda Centre at the University of Sydney. Dr. Birrell's research examines the links between alcohol use and mental health in adolescents. She has extensive experience with substance use and mental health prevention programs and she has conducted systematic reviews of substance use-related mobile apps and app development. 


\section{KATRINA CHAMPION}

Dr. Katrina Champion is a NHMRC Early Career Fellow and Research Fellow at the Matilda Centre at the University of Sydney. Katrina's research aims to develop and evaluate digital interventions to improve the physical and mental health of adolescents. She has been involved in multiple school-based trials to prevent substance use and related harms among secondary school students. She currently leads the Health4Life Study, an evaluation of an online health intervention to reduce chronic disease risk among adolescents.

\section{NICOLA NEWTON}

A/Prof. Nicola Newton is the Director of Prevention at the Matilda Centre for Research in Mental Health and Substance Use at the University of Sydney. Nicola is the Prevention Lead at the NHMRC Centre for Research Excellence in Prevention and Early Intervention in Mental Illness and Substance Use (PREMISE) and has extensive experience in developing and evaluating innovative adolescent substance use prevention programs in an effort to promote positive healthy behaviors among young people. 